\title{
The St Vincent parrot, an endangered Caribbean bird
}

Frank Lambert

The future of the St Vincent parrot is seriously threatened. It is still captured for the pet trade, its forest habitat is being destroyed and the remnant populations are subject to natural catastrophes. In 1979 Mt Soufrière, the island's active volcano, erupted and many parrots died from the effects of toxic gases. In 1980 Hurrican Allen damaged forest in the east of the island. In 1982 the ICBP, concerned about the effect of these incidents on an already precarious parrot population, promoted an expedition from the University of East Anglia to investigate and FFPS was among those that helped finance it.

The St Vincent parrot Amazona guildingii is listed as endangered in the Bird Red Data Book (King, 1981). It is an island endemic, threatened by habitat destruction and the pet trade. Confined to the humid montane forests of St Vincent, in the Lesser Antilles, its numbers have been gradually dwindling.

In 1978 the population was estimated at $525 \pm 75$ individuals (Nichols, 1980). In April of the following year, St Vincent's active volcano, Mt Soufrière, erupted and parrots were found dying from the effects of toxic gases as far south as the Buccament valley (Nichols, 1980). Seventeen months later, in August 1980, Hurricane Allen hit St Vincent, flattening virtually all of the island's banana crop (upon which the economy is dependent) and damaging much of the forest in the windward (easterm) part of the island (Lambert, 1983).

Although St Vincent parrots have undoubtedly faced such natural catastrophes in the past, 34 diminishing areas of forest mean that the effects of such events on the parrot population today are likely to be much greater. Even at the end of the last century, when the forest was more extensive, hurricanes must have caused serious population changes: Clark (1905) discussing the 'great hurricane' of 1898 , related that St Vincent parrots 'Strayed into the smaller towns in so helpless a condition that they fell prey to the villagers', and furthermore that 'on the next day the island appeared as if it had been swept by fire; there was not a leaf nor any green thing in sight'. Presumably, such a hurricane would have reduced parrot food resources to a critically low level over much of the forest.

Concern following the most recent eruption and hurricane prompted the International Council for Bird Preservation (ICBP) to promote an expedition to St Vincent in order to determine the effects of these natural catastrophes on the St Vincent parrot and to investigate other threats to their survival. The expedition, from the University of East Anglia, surveyed the whole range of $A$. guildingii during two-and-a-half months of intensive field-work in 1982.

It was found that the population of parrots had declined by some 20 per cent since 1978 , with only some $420 \pm 50$ remaining (Lambert, 1983). Of the six areas where parrots were present in 1978 , only four held parrots in 1982. Two of these localities had more parrots than in 1978, whilst the other two had fewer. Habitat destruction was considered the main cause for decline, although the pet trade was also playing a part.

Contrary to expectations, the eruption of Soufrière had not caused any obvious damage to

Oryx Vol 19 No 1 


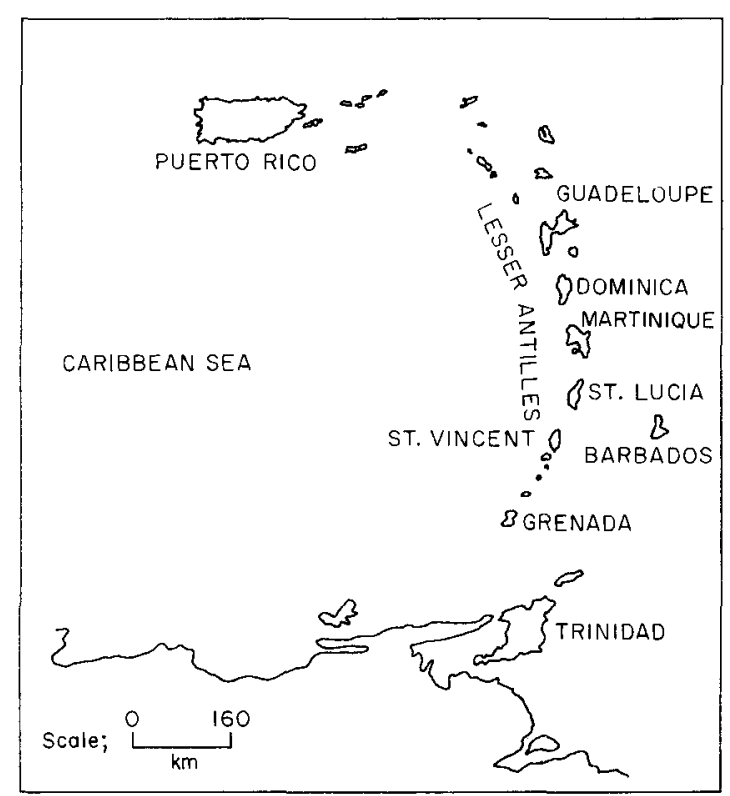

The Lesser Antilles showing the position of St Vincent.

forested areas adjacent to the volcanic crater, although parrots had evacuated these areas. Hurricane Allen, on the other hand, had caused important structural changes to the windward forests, and here too parrot numbers had declined. The hurricane removed substantial numbers of the older trees, particularly those of Dacryodes excelsa, a species which begins to hollow out once mature. This tree is not only an important source of food for parrots but also, when hollow, provides ideal parrot nesting sites, and indeed may be the most favoured tree in this respect. Hurrican Allen must therefore have reduced the quality of windward forest habitat for the parrots, although it is impossible to quantify the change.

Parrot numbers in the forested south-western valley systems of Buccament, Wallilabou and Cumberland had increased since the 1978 estimate, and together held about 64 per cent of the total population in 1982 . This increase may in part be due to an influx of birds from more northerly forests following the 1979 eruption, and from the windward forests following the 1980 hurricane. Under normal circumstances there appears to be little, if any, movement of parrots between the windward and leeward forests, which are separated by high mountain ridges.

The south-western forests contain better parrot habitat, being of greater stature, more sheltered (from prevalent westerlies) and less disturbed by man. There also appear to be far more large, old trees such as D. excelsa, and therefore potentially more breeding sites. It seems feasible that parrots arrriving in this area during and following the volcanic eruption and hurricane may have stayed rather than return to suboptimal habitats. There may now be as few as 80 parrots remaining in the windward forests (Lambert, 1983).

Future volcanic eruptions and hurricanes are likely to pose very serious threats to the survival of the St Vincent parrot. However, the most serious threat comes not from these, but from man. Forest is being cleared for both shifting and permanent agriculture, and forest hardwoods are selectively removed for charcoal burning. This all continues largely unchecked. The Forestry Division of St Vincent, whose responsibility it is to deal with these, often illegal, practices, is far too small to enforce laws adequately.

High unemployment has led to an increase in the practice of shifting agriculture. In many areas, especially in the windward, forests have been transformed to patchy mosaics of cleared, regenerating and mature forest. In the future only land unsuitable for cultivation or in inaccessible areas will remain forested, but even within such areas, selective logging for charcoal burning is likely to increase. The most commonly felled trees for the latter purpose appear to be 'middle-aged' $D$. exelsa, whose importance as a source of food and, in old age, nest-sites, has already been stressed. The overall effect of such unchecked practices will clearly be a dramatic decline in future breeding sites. Unfortunately other forms of fuel are prohibitively expensive, and unless an alternative cheap source is found, charcoal burning will inevitably and necessarily continue.

Another serious, though unquantified, threat is the pet trade. Fledgling parrots are taken by local woodsmen and sold to both professional pet dealers and naive tourists. In 1982 we found eight first year birds in captivity on the island and suspected that many more may already have been 
illegally exported, or remained undetected. A We also located a number of exotic orangenumber of Vincentians also own older parrots as winged parrots Amazona amazonica which had status symbols. been illegally imported and locally sold as St

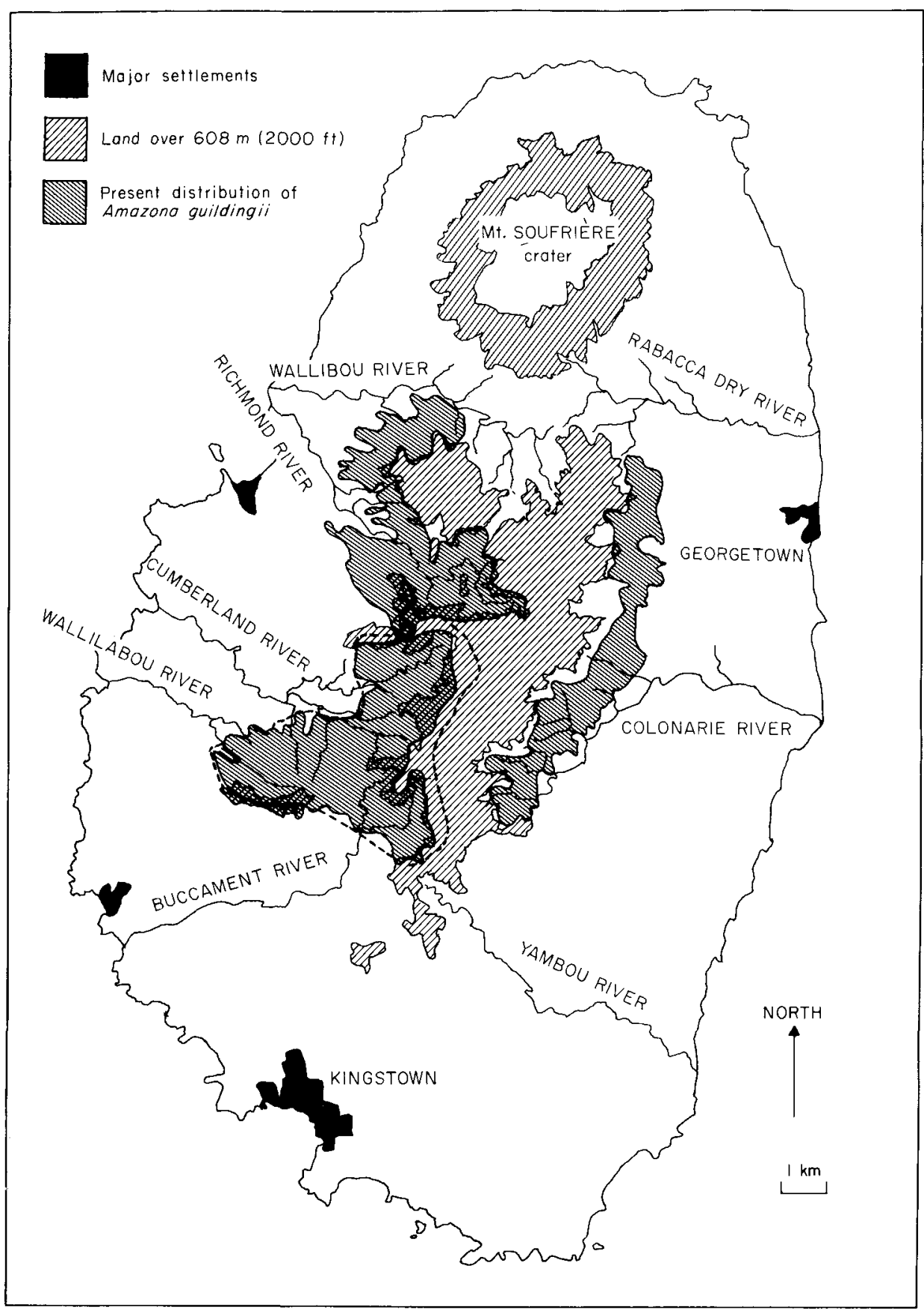

Detailed map of St Vincent. The dashed line encloses the area proposed as a parrot reserve by the 1982 expedition. 
Vincent parrots. Should some of these birds escape and establish a feral population, they could become an agricultural pest (as they are beginning to be on Trinidad) and may also threaten the long-term survival of the St Vincent parrot through competition for nesting sites.

Despite these threats there still exists sufficient habitat for the birds. The 1982 expedition stimulated considerable local interest, and it is hoped that this new awareness may help the parrots' future. The St Vincent Forestry Division was particularly concerned and have initiated a scheme to register all captive parrots in the hope of detecting birds destined for the pet trade. Indeed, two young birds were confiscated from a yacht as it was about to leave the island.

Unfortunately, however, it seems unlikely that confiscated birds can be reintroduced into the wild, and they are destined to a life in captivity. Such birds could, however, perform an educative function and simultaneously form a captive breeding stock. There have been a number of captive-breeding programmes involving $\mathrm{St}$ Vincent parrots, but to date they have met with little success, and it seems unlikely that enough progeny could be produced to develop techniques for their successful release into the wild.

The 1982 expedition made a number of recommendations for the conservation of $A$. guildingii, which have been submitted to World Wildlife Fund (WWF) and the St Vincent Government. It is hoped that they will be considered and incorporated into proposals for the establishment of a parrot reserve. Such a reserve, preferably located in the forests of the south-west, would also protect important watersheds, provide local employment and act as a focus for education. On nearby St Lucia, a WWF-sponsored reserve, protecting the endangered St Lucia parrot Amazona versicolor, has met with great success, while the associated tourist industry provides some income towards the reserve's running costs.

Unless sufficient areas are set aside, then it may be that a future hurricane will extirpate these beautiful parrots. Although agriculture may leave small, isolated patches of forest where parrots can continue to survive, these will necessarily be in exposed terrain, unprotected from the devastating effects of a hurricane. Parrots initially surThe St Vincent parrot viving such an event are unlikely to live through subsequent food shortages, because all the remaining patches of forest would be seriously damaged, and food unavailable for short-term survival.

Six species of parrot once inhabited the Lesser Antillean islands (Greenway, 1967). Two are already extinct, and all the rest, including the St Vincent parrot, are seriously threatened. The various governments in the Lesser Antilles, including that of St Vincent, are all very positive in their attitudes towards conservation, but being so poor it is difficult for them to create the necessary reserves to protect their forests and wildlife adequately. Unless financial assistance is forthcoming, the St Vincent parrot will eventually, but undoubtedly, disappear forever.

\section{Acknowledgments}

This report is based on work caried out by the UEA, ICBP St Vincent Parrot Expedition 1982. The expedition members were Martin Kelsey, Tom Langton, Kevin Morgan and myself. The expedition was sponsored by the University of East Anglia, British Ecological Society, Ernest Kleinwort Charitable Trust, Condor Conservation Trust, World Expeditionary Association, Gilchrist Educational Trust, Fauna and Flora Preservation Society, Barbinder Trust, Mr Henry Usborne, Leeward Island Air Travel and Intemational Council for Bird Preservation; to all these we are extremely grateful. We would also like to thank Dr N.J. Collar of ICBP; the Hon V.I. Beeche, Minister for Trade and Agriculture on St Vincent; Calvin Nichols and the other members of the St Vincent Forestry Division, who all assisted us in many ways.

\section{References}

Clark, A.H. 1905. Birds of the southern Lesser Antilles. Proc. Boston Soc. Nat. Hist. 32, 203-312.

Greenway, J.C. 1967. Extinct and Vanishing Birds of the World. Serial Publication No. 13. American Committee for International Wildlife Protection, New York.

King, W.B. 1981. Endangered Birds of the World. The ICBP Red Data Book. Smithsonian Institution, Washington DC.

Lambert, F.R. 1983. Report on the status of St Vincent Parrots in 1982. ICBP Study Report No. 3. Cambridge.

Nichols, T.D. 1980. St Vincent Amazon (Amazona guildingii): predators, clutch size, plumage polymorphism, effect of the volcanic eruption, and population estimate. In Conservation of New World Parrots (Ed. R.F. Pasquier), pp. 197-208. ICBP Technical Publication No. 1. Smithsonian Institution, Washington DC.

Frank Lambert, Institute of South-East Asian Biology, Department of Zoology, University of Aberdeen, UK.

Present address: Jabatan Zoologi, Universiti Malaya, Kuala Lumpur, Malaysia. 